\title{
Energy cost savings based on the UPS
}

\author{
Phu Tran Tin ${ }^{1}$, Duy Hung $\mathrm{Ha}^{2}$, Minh Tran ${ }^{3}$, Q. S. Vu \\ ${ }^{1}$ Faculty of Electronics Technology, Industrial University of Ho Chi Minh City, Vietnam \\ ${ }^{2}$ Wireless Communications Research Group, Faculty of Electrical and Electronics Engineering, \\ Ton Duc Thang University, Vietnam \\ ${ }^{3}$ Optoelectronics Research Group, Faculty of Electrical and Electronics Engineering, \\ Ton Duc Thang University, Vietnam \\ ${ }^{4}$ National Key Laboratory of Digital Control and System Engineering, Vietnam
}

\begin{tabular}{l} 
Article Info \\
\hline Article history: \\
Received Dec 5, 2019 \\
Revised Feb 21, 2020 \\
Accepted Feb 29, 2020 \\
\hline
\end{tabular}

Keywords:

Energy storage

Linear programming problem

Optimization

Simplex-method

\begin{abstract}
Energy-saving, improving energy efficiency, and finding a new efficient way to use energy are considered as an urgent problem in over the world. In this paper, we consider the economics of energy use in combination with energy storage units where two forms of electricity exist in the power system. Then the problem of optimizing the installation capacity (to optimize the investment costs for energy storage) is presented and investigated in connection with the conversion systems. The topic opens a very significant result, including the introduction of a mathematical model to calculate the simulation in optimizing the installation capacity of the equipment in the system, multi-source power, as well as voltage and power stability benefits.
\end{abstract}

Copyright $@ 2020$ Institute of Advanced Engineering and Science. All rights reserved.

\section{Corresponding Author:}

Duy-Hung Ha,

Wireless Communications Research Group,

Faculty of Electrical and Electronics Engineering,

Ton Duc Thang University,

Ho Chi Minh City, Vietnam.

Email: haduyhung@tdtu.edu.vn

\section{INTRODUCTION}

This paper considers the problem, which related to the research project to improve economic and technical efficiency in the current period of the Russian Federation power systems. In fact, there have a two-price mechanism exists (electricity prices vary between peak and off-peak times) it is possible to receive some degree of energy cost savings when installing units. energy storage [1-12]. In this paper, we proposed the followings problems as 1) The level of cost savings of how energy is achieved and how to control the operation of the UPS to save costs; 2) The correlation of the capacity components of the load, the capacity of the supply network, the capacity of the converter and the capacity of the energy storage to how to save maximum cost; 3 ) the ability to stabilize the voltage in the system.

These problems are the aim of this paper. The investment and operation of an energy storage device are significant for the owner of the load if it reduces energy costs. The power supply system can also finance the investment and operation of storage devices if it helps reduce the unevenness of the network. In optimizing energy consumption costs, it means that we will consider the issue of energy efficiency from the owners' perspective $[13,14]$.

This paper develops and solves the problem of determining the minimum cost of energy consumption when the ratios of power consumption of load components, converter power, and storage capacity amount. Assume that energy consumers consume only active power. The load characteristics are 
maximum during the day and vary between days in a week. The capacity of the load consists of two parts; the fixed component includes essential loads, and the component can be changed, that is, can shift the time of use. The unit, the load, and the power from the grid are connected to the distribution control system (including charge/discharge and converter controllers). To solve this problem, we put the problem of solving linear programming problems with thousands of variables. The system's working mode is simulated for a week with a discrete distance of 12 minutes. The results of the problem have proved that the use of UPSs brings economic efficiency of 5-25\%, without taking into account the cost of the system, storage devices, and associated energy converters. The assessment of the overall economic efficiency of this topic must be investigated for all the above factors. In the general conclusion of the paper confirms that at present due to the price of the variable and energy storage devices is still high compared to the cost savings brought by the two-price mechanism, the use of such devices are inefficient. However, the topic opens a very significant result, including the introduction of a mathematical model to calculate the simulation in optimizing the installation capacity of the equipment in the system, multi-source power, as well as voltage and power stability benefits. The rest of the paper is constructed as the following. The mathematical formulation is proposed in the second section. In the third section, some numerical results and discussions are presented and analyzed. The last section draws some conclusions from this research.

\section{MATHEMATICAL FORMULATION}

In this section, we give the quantities describe the problem and their limitations. First, to make it clear, we introduce these quantities as continuous functions over time, then we take a discrete step over time, and all quantities describe the problem become vectors whose components will be valuable at discrete points. For UPS, $P_{\text {bat max }}, P_{\text {bat }}(t), W_{\text {bat max }}, W_{\text {bat }}(t)$ are corresponding to the capacity of the power converter suitable to connect the unit and the grid. Instantaneous generating/receiving capacity of the unit must be synchronized with the capacity of the inverter. The quantities describe the electrical storage part are,

$$
\begin{aligned}
& -P_{\text {bat max }} \leq P_{\text {bat }}(t) \leq P_{\text {bat max }} \\
& 0 \leq W_{\text {bat }}(t) \leq W_{\text {bat max }}
\end{aligned}
$$

where $\quad W_{\text {bat }}(t)=\int_{0}^{t} P_{\text {bat }}(t) d t+W_{\text {bat }}(0)$

It should be noted that the maximum capacity and capacity of the battery must be taken according to the charge/discharge limits of the battery, within which the UPS operates correctly, i.e. depending on the charge/discharge characteristics according to the condition of the energy-saving unit. These limits are different for each type of battery used as shown in [15]. If $W_{\text {bat }}(0)=0$, then

$$
W_{\text {bat }}(t)=\int_{0}^{t} P_{\text {bat }}(t) d t
$$

Regarding the capacity taken from the grid $P_{\text {net max }}, P_{\text {net }}(t)$ are the maximum power allowed from the grid and instantaneous power, we have:

$$
0 \leq P_{\text {net }}(t) \leq P_{\text {net } \max }
$$

For load, $P_{\text {load }}(t)$ is the instantaneous power of the initial load. As mentioned above, there are two components $P_{\text {const }}(t)$ and $P_{\text {var }}(t)$ as shown in the below equation:

$$
P_{\text {load }}(t)=P_{\text {const }}(t)+P_{\text {var }}(t)
$$

where $P_{\text {const }}(t)$ is the load component is always present and cannot be changed at use time, i.e. its graph does not change after optimization; $P_{\text {var }}(t)$ is the component may change when it is used, i.e. its graph will be 
changed after optimization. The load energy $W_{\text {load }}$ consumed from $t=0$ to $t=T$, with $\mathrm{T}$ the simulation time, in this problem we simulate the system operating within a week, we have [16].

$$
W_{\text {load }}=\int_{0}^{T} P_{\text {load }}(t) d t=\int_{0}^{T} P_{\text {const }}(t) d t+\int_{0}^{T} P_{\text {var }}(t) d t=W_{\text {const }}+W_{\text {var }}
$$

where

$$
W_{\mathrm{var}}=\int_{0}^{T} P_{\mathrm{var}}(t) d t
$$

Power balance equation is given by:

$$
P_{\text {bat }}(t)+P_{\text {net }}(t)=P_{\text {load }}(t) \text { or }-P_{\text {var }}(t)+P_{\text {bat }}(t)+P_{\text {net }}(t)=P_{\text {const }}(t)
$$

We take into account the vectors $P_{\mathrm{var}}, P_{\mathrm{bat}}, P_{\text {net }}$, whose elements are values corresponding to quantities $P_{\text {var }}(t), P_{\text {bat }}(t), P_{\text {net }}(t)$ at discrete point $t_{k}:\left\{t_{1}=0 ; t_{k}=t_{k-1}+h ; t_{N}=T\right\}$, with $\mathrm{h}$ is the observation step during simulation - 12 minutes. Next, to make writing quantities simpler, we denote $P_{\text {var }, k}=P_{\text {var }}\left(t_{k}\right), P_{\text {bat }, k}=P_{\text {bat }}\left(t_{k}\right), P_{\text {net }, k}=P_{\text {net }}\left(t_{k}\right)$. Then we have:

$$
\mathbf{P}_{\mathrm{var}}=\left[\begin{array}{c}
P_{\mathrm{var}, 1} \\
P_{\mathrm{var}, 2} \\
\mathrm{M} \\
P_{\mathrm{var}, N}
\end{array}\right] ; \quad \mathbf{P}_{\mathrm{bat}}=\left[\begin{array}{c}
P_{\mathrm{bat}, 1} \\
P_{\mathrm{bat}, 2} \\
\mathrm{M} \\
P_{\mathrm{bat}, N}
\end{array}\right] ; \quad \mathbf{P}_{\mathrm{net}}=\left[\begin{array}{c}
P_{\text {net }, 1} \\
P_{\text {net }, 2} \\
\mathrm{M} \\
P_{\text {net }, N}
\end{array}\right]
$$

Suppose K ( $t$ - - the price of electricity purchased from the grid changes according to the time of use according to a known rule. In this problem, we take the electricity price in the city of Saint-Petersburg, May 2019. Daytime prices are 7.6 cents / kWh and at night 4.4 cents / kWh. Similarly, we include the price vector so that we can write equations in the form of matrices. The cost for the energy storage unit will be calculated from the capacity and the optimal battery capacity received during the simulations. The objective function can be formulated as

$$
f=\mathbf{K}^{t} \mathbf{P}_{\text {net }} \rightarrow \min
$$

The limits in (8) indicate the fact that the total power taken from the grid and the unit is equal to the load capacity at any given time. Hence, in vector form, (7) is rewritten as

$$
W_{\mathrm{var}}=\int_{0}^{T} P_{\mathrm{var}}(t) d t=\sum_{n=1}^{N} P_{\mathrm{var}, h} h=h \cdot \mathbf{1}^{t} \cdot \mathbf{P}_{\mathrm{var}}=B_{1}=W_{\text {load }}-W_{\text {const }}
$$

where 1 - Unit vectors of the corresponding size. From the hypothesis that the initial state $W_{\text {bat }}(0)$ of the unit and the same $W_{\text {bat }, N}$ - the remaining power of the unit are equal, we get the limits:

$$
W_{\text {bat }}=W_{\text {bat }}(0)+h \cdot \mathbf{1}^{t} \cdot \mathbf{P}_{\text {bat }}=W_{\text {bat }, 1}+B_{2}=W_{\text {bat }, N} \text { hay } h \cdot \mathbf{1}^{t} \cdot \mathbf{P}_{\text {bat }}=B_{2}=W_{\text {bat }, N}-W_{\text {bat }}(0)
$$

Then (8) can be reformulated as the following

$$
\left[\begin{array}{lll}
-\mathbf{E} & -\mathbf{E} & \mathbf{E}
\end{array}\right] \cdot\left[\begin{array}{c}
\mathbf{P}_{\text {var }} \\
\mathbf{P}_{\text {bat }} \\
\mathbf{P}_{\mathbf{X}}
\end{array}\right]=\left[\begin{array}{c}
P_{\text {const }, 1} \\
P_{\text {const }, 2} \\
\mathrm{M} \\
P_{\text {const }, N}
\end{array}\right]=\mathbf{B}_{3}
$$


Where $\mathbf{E}$ - matrix unit. Finally, we have

$$
\left[\begin{array}{ccc}
h \cdot \mathbf{1}^{t} & \mathbf{0} & \mathbf{0} \\
\mathbf{0} & h \cdot \mathbf{1}^{t} & \mathbf{0} \\
-h \cdot \mathbf{E} & -h \cdot \mathbf{E} & h \cdot \mathbf{E}
\end{array}\right] \cdot\left[\begin{array}{l}
\mathbf{P}_{\text {var }} \\
\mathbf{P}_{\text {bat }} \\
\mathbf{P}_{\text {net }}
\end{array}\right]=\left[\begin{array}{c}
B_{1} \\
B_{2} \\
\mathbf{B}_{3}
\end{array}\right] \Rightarrow \mathbf{A X}=\mathbf{B}
$$

where $\mathbf{0}$ - vectors have no corresponding dimensions.

In (3), we denote that the UPS and converters have no loss then

$$
0 \leq W_{\text {bat }, \mathrm{n}}=W_{\text {bat }}(0)+\sum_{i=1}^{n} P_{\text {bat }, i} h \leq W_{\text {bat } \max } ; \quad n=\overline{1, N}
$$

Or in the matrix form as

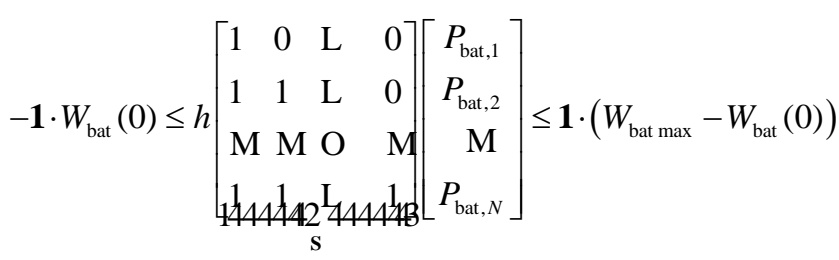

$$
\begin{aligned}
& \text { Or }-\mathbf{1} \cdot \frac{W_{\text {bat }}(0)}{h} \leq \mathbf{S} \cdot \mathbf{P}_{\text {bat }} \leq \mathbf{1} \cdot \frac{W_{\text {bat max }}-W_{\text {bat }}(0)}{h} \text {, then } \\
& {\left[\begin{array}{c}
\mathbf{S} \\
-\mathbf{S}
\end{array}\right] \mathbf{P}_{\text {bat }} \leq \frac{1}{h}\left[\begin{array}{c}
\mathbf{1} \cdot\left(W_{\text {bat } \max }-W_{\text {bat }}(0)\right) \\
\mathbf{1} \cdot W_{\text {bat }}(0)
\end{array}\right]}
\end{aligned}
$$

Finally, we have

$$
\left[\begin{array}{c}
\mathbf{0} \\
\mathbf{S} \\
-\mathbf{S} \\
\mathbf{0}
\end{array}\right] \cdot\left[\begin{array}{l}
\mathbf{P}_{\text {var }} \\
\mathbf{P}_{\text {bat }} \\
\mathbf{P}_{\text {net }}
\end{array}\right] \leq \frac{1}{h}\left[\begin{array}{c}
\mathbf{0} \\
\mathbf{1} \cdot\left(W_{\text {bat max }}-W_{\text {bat }}(0)\right) \\
\mathbf{1} \cdot W_{\text {bat }}(0) \\
\mathbf{0}
\end{array}\right] \Rightarrow \mathbf{C X} \leq \mathbf{D}
$$

We re-list the entire mathematical model of the problem to be solved as

$$
\left\{\begin{array}{c}
0 \leq P_{\text {var }}(t) \leq P_{\text {net max }}-P_{\text {load max }} \\
-P_{\text {bat max }} \leq P_{\text {bat }}(t) \leq P_{\text {bat max }} \\
0 \leq P_{\text {net }}(t) \leq P_{\text {net max }}
\end{array} \quad\left[\begin{array}{c}
\mathbf{0} \\
\mathbf{- 1} \cdot P_{\text {bat max }} \\
\mathbf{0}
\end{array}\right] \leq\left[\begin{array}{l}
\mathbf{P}_{\text {var }} \\
\mathbf{P}_{\text {bat }} \\
\mathbf{P}_{\text {net }}
\end{array}\right] \leq\left[\begin{array}{c}
\mathbf{1} \cdot\left(P_{\text {load }}-P_{\text {const }}\right) \\
\mathbf{1} \cdot P_{\text {bat max }} \\
\mathbf{1} \cdot P_{\text {net max }}
\end{array}\right]\right.
$$

The problem (12) is formed from the problem (9) with conditions in the form of equality (10) and inequalities (11) related to linear programming problems, and to solve problems of this type, we apply the simplex method as in [17-21]. The total number of variables when simulating the system within a week with a 12-minute observation step is 2520 variables.

\section{NUMERICAL RESULTS AND DISCUSSION}

Figure 1(a) corresponds to the case when $P_{\text {var }}(t)=P_{\text {const }}(t)$, when the power output is interchangeable and cannot be changed equally. As you can see, the actual UPS is almost unused (curve $\left.W_{\text {bat }}(t)\right)$. The capacity of the UPS can then be reduced to $10 \mathrm{kWh}$. The economic benefits are about $20 \%$ of the original. Figure $1(\mathrm{~b})$ corresponds to the case $P_{\mathrm{var}}(t)=0.2 P_{\text {const }}(t)$. It can be seen that the UPS is used very 
actively (maximum battery capacity is $45 \mathrm{kWh}$, and its capacity is $15 \mathrm{~kW}$ ), activities consume more energy comfortably for consumers. UPSs and converters are used very actively. Accordingly, the losses in the equipment and the depreciation costs of these devices (not included by us) can be significant [22-25]. To verify the results graphically, we turn to relative values as shown in (13).

$$
\hat{P}_{\text {net max }}=\frac{P_{\text {net max }}}{P_{\text {load max }}}, \quad \hat{P}_{\text {load var }}=\frac{P_{\text {load var }}}{P_{\text {load max }}}, \quad \hat{P}_{\text {bat max }}=\frac{P_{\text {bat max }}}{P_{\text {load max }}}
$$

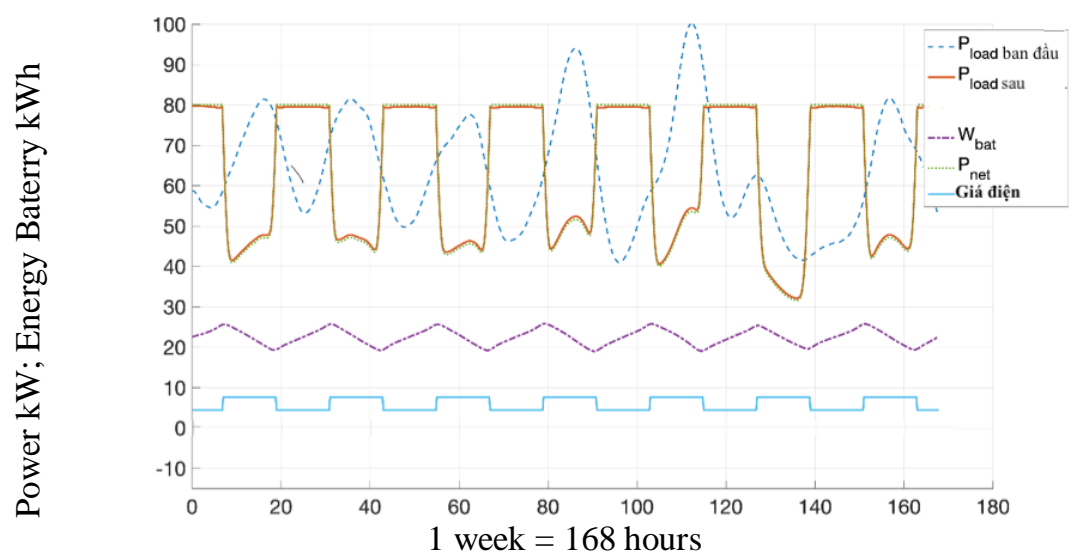

(a)

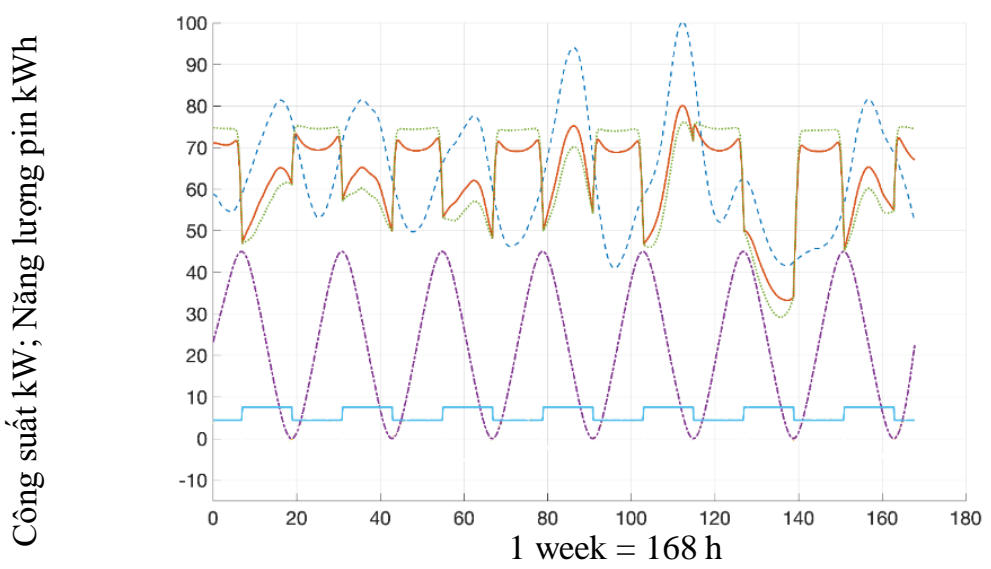

(b)

Figure 1. Optimize electricity consumption costs when: $a)-P_{\text {var }}(t)=P_{\text {const }}(t)$ and $\left.b\right) P_{\text {var }}(t)=0.2 P_{\text {const }}(t)$

In Table 1, we present the results of several dozen calculations performed for different ratios concerning the relative values above. On the vertical axis of all graphs, the percentage of energy cost savings percentage (hereinafter F) is consumed from the network. The third line in each cell of Table 1 gives the ratios of the word parameters (13). As can be seen from the graphs, the increase in converter capacity (corresponding to the capacity of the unit) reduces the cost of electricity consumption ( $F$ increases). This result is easily predictable. However, as can be seen from the diagrams (first panel of table 1) such as $\mathrm{F}=25 \%$ when the load capacity of $100 \mathrm{~kW}$ is more than $150 \mathrm{kWh}$. The analysis of the first cell of table 1 has shown that $\mathrm{F}$ decreases as the maximum power from the grid decrease. This is explained by the fact that, at the maximum power allowed from the grid, there is not enough power per charge on the unit, and of course, its efficiency is low even with the capacity of the converter as well as of the large UPS. When the maximum power available from the grid increases, F increases linearly with the capacity of the unit. The second cell shows the effect of quantities on the efficiency of the use of uninterruptible power supplies. Here $\mathrm{F}$ also decreases as the maximum power taken from the grid decreases, and when within the same maximum power of the grid, the constant component decreases. An analysis of the last cell 
of the table also shows a similar result. Thus, the general conclusion is that to save significant energy costs can only be achieved with the maximum capacity of the high grid.

Table 1. The level of economic efficiency depends on relative quantities (13)

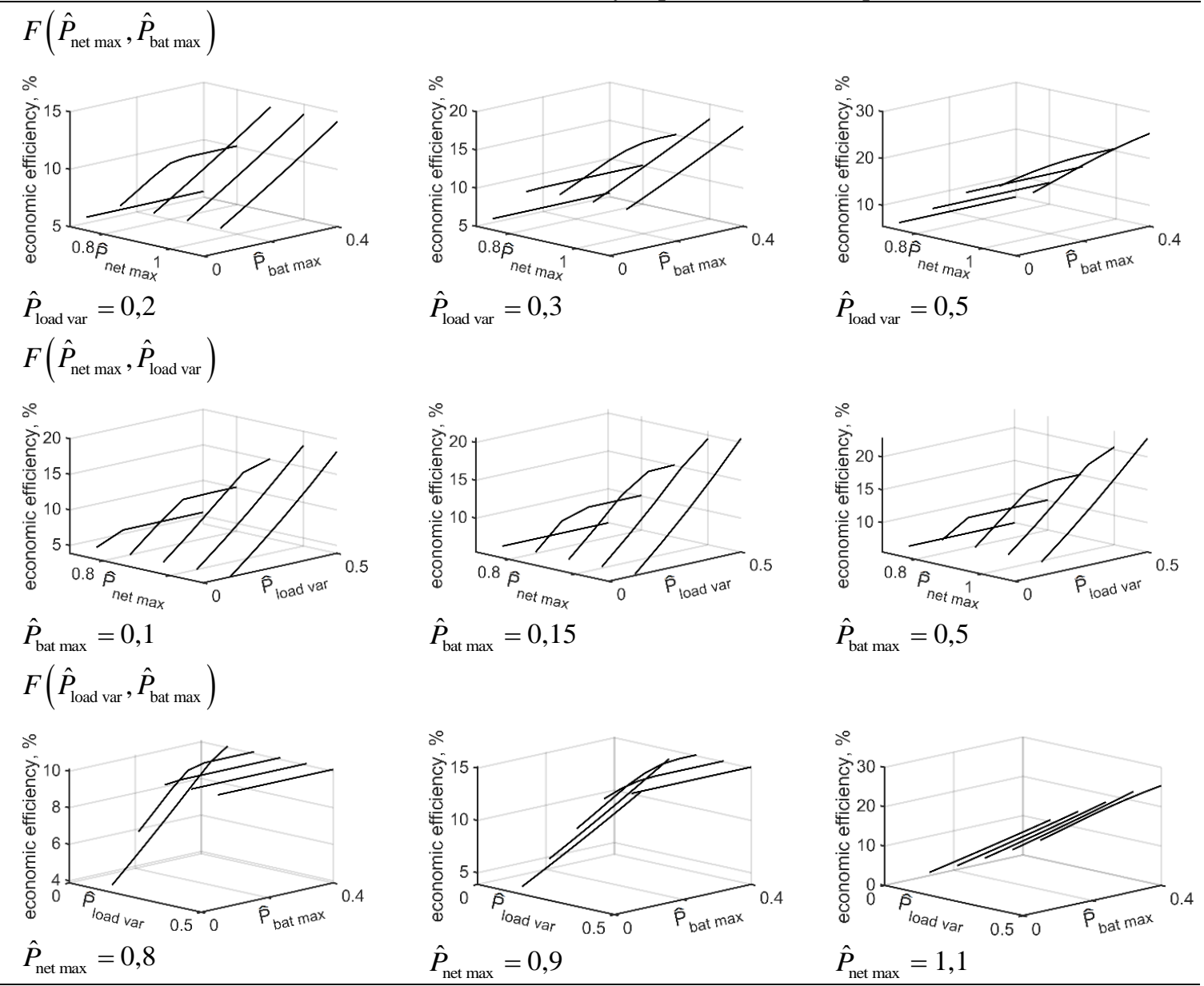

\section{CONCLUSION}

The results show that even with reasonably simple assumptions, the use of a UPS helps to reduce energy costs by $5-25 \%$. At the same time, the capital cost of additional equipment (the unit and the converter connecting it to the network) is estimated to be significant. The energy efficiency is significant (10 percent or more) when the variable power component of the load accounts for 10 percent or more of the maximum power taken from the grid. Therefore, the question of the efficiency of energy cost savings when using the UPS and the two-price mechanism receives the answer (according to our research) is insignificant because the operating costs and the costs of investing in consumer electricity storage devices are equivalent to the costs saved by increasing electricity consumption (including saving electricity) at times of low prices and reducing consumption. Electricity at a time of high prices. The situation is likely to change significantly if the owner has the opportunity to use alternative (renewable) energy sources. We intend to consider this issue further.

\section{REFERENCES}

[1] H. Chen, B. Wei and D. Ma, "Energy Storage and Management System With Carbon Nanotube Supercapacitor and Multidirectional Power Delivery Capability for Autonomous Wireless Sensor Nodes," in IEEE Transactions on Power Electronics, vol. 25, no. 12, pp. 2897-2909, Dec. 2010.

[2] V. Subramanian, et al., "Printed electronics for low-cost electronic systems: Technology status and application development," ESSCIRC 2008 - 34th European Solid-State Circuits Conference, Edinburgh, pp. 17-24, 2008.

[3] V. A. Boicea, "Energy Storage Technologies: The Past and the Present," in Proceedings of the IEEE, vol. 102, no. 11, pp. 1777-1794, Nov. 2014. 
[4] J. Yao, H. Li, Y. Liao, and Z. Chen, "An improved control strategy of limiting the DC-link voltage fluctuation for a doubly-fed induction wind generator," IEEE Trans. Power Electron., vol. 23, no. 3, pp. 1205-1213, May 2008.

[5] A. Timbus, M. Liserre, R. Teodorescu, P. Rodriguez, and F. Blaabjerg, "Evaluation of current controllers for distributed power generation systems," IEEE Trans. Power Electron., vol. 24, no. 3, pp. 654-664, Mar. 2009.

[6] L. Maharjan, S. Inoue, H. Akagi, and J. Asakura, "State-of-charge (SOC)-balancing control of a battery energy storage system based on a cascade PWM converter," IEEE Trans. Power Electron., vol. 24, no. 6, pp. 1628-1636, Jun. 2009.

[7] Y. W. Li and C. N. Kao, "An accurate power control strategy for power-electronics-interfaced distributed generation units operating in a low-voltage multibus microgrid," IEEE Trans. Power Electron., vol. 24, no. 12, pp. 2977-2988, Dec. 2009.

[8] I. Park, et al, "Nanoscale Patterning and Electronics on Flexible Substrate by Direct Nanoimprinting of Metallic Nanoparticles," Advanced Materials, vol. 20, pp. 489 - 496, 2008.

[9] A.V. Boicea, G. Chicco, and P. Mancarella, "Optimal operation at partial load of a $30 \mathrm{~kW}$ natural gas microturbine cluster," Buletinul Stiintific al Universitatii Politehnica Bucuresti, Seria C, vol. 73, no. 1, pp. 211-222, Mar. 2011.

[10] S. Shepard, "Vehicle to Grid Frequency Regulation Revenue Will Surpass \$190 Million Annually by 2022," Boulder, CO, USA: Navigant Res., Oct. 2013.

[11] K. Yang and A. Walid, "Outage-storage tradeoff in frequency regulation for smart grid with renewables," IEEE Trans. Smart Grid, vol. 4, no. 1, pp. 245-252, Mar. 2013.

[12] H. Zhang, "A battery storage device for distributed hybrid-powered smart grid system and control method thereof," European Patent 2645522 A1, Oct. 2, 2013.

[13] Stone, R.E. and Tovey, C.A, "Erratum: The simplex and projective scaling algorithms as iteratively reweighted least-squares methods," SIAM Review, pp. 220-237, 1991.

[14] Vazquez, S., Lukic, S. M., Galvan, E., Franquelo, L. G. and Carrasco, J. M, "Energy storage systems for transport and grid applications," IEEE Transactions on Industrial Electronics, pp. 3881-3895. 2010.

[15] Guide, I, "IEEE Guide for Selecting, Charging, Testing, and Evaluating Lead-Acid Batteries Used in Stand-Alone Photovoltaic (PV) Systems," in IEEE Std 1361-2014 (Revision of IEEE Std 1361-2003), pp. 1-39, Jun. 2014.

[16] Demirchyan, K., Neumann, L. and Korovkin, N, “Theoretical foundations of electrical engineering," SPB: Peter, 2009.

[17] Adler, I., Christos, P. and Rubinstein, A, “On Simplex Pivoting Rules and Complexity Theory,” International Conference on Integer Programming and Combinatorial Optimization, arXiv: Lecture Notes in Computer Science, pp. 13-24, 2014.

[18] Hansen, T. and Zwick, U, "An Improved Version of the Random-Facet Pivoting Rule for the Simplex Algorithm," Proceedings of the Forty-seventh Annual ACM Symposium on Theory of Computing, pp. 209-218, 2015.

[19] Klee, V. and Minty, G.J, "How good is the simplex algorithm?," Los Angeles, Calif, In Shisha, Oved (ed.). Inequalities III (Proceedings of the Third Symposium on Inequalities held at the University of California, pp. 1-9, Sep. 1972.

[20] Schrijver, A, "Theory of Linear and Integer Programming," New York: John Wiley \& sons, 1998.

[21] Stone, R.E. and Tovey, C.A, "The simplex and projective scaling algorithms as iteratively reweighted least-squares methods," SIAM Review, pp. 220-237, 1991.

[22] Mirshekarpour, B. and Davari, S.A, "Efficiency Optimization and Power Management in a Stand-Alone Photovoltaic (PV) Water Pumping System," 7th Power Electronics, Drive Systems \& Technologies Conference (PEDSTC 2016), Tehran, Iran, pp. 427-433, 2016.

[23] Priyono, W., Wijaya, D.F., Firmansyah, E, "Study and Simulation of a Hybrid Stand-alone PV System for Rural Telecommunications System," 2018 3rd International Conference on Information Technology, Information Systems and Electrical Engineering (ICITISEE), Yogyakarta, Indonesia, pp. 418-422, 2018.

[24] Ribeiro, P. F., Johnson, B. K., Crow, M. L., Arsoy, A. and Liu, Y, "Energy storage systems for advanced power applications," Proceedings of the IEEE, pp. 1744-1756, 2001.

[25] Tran, V.H. and Coupechoux, M, "Cost-constrained Viterbi Algorithm for Resource Allocation in Solar Base Stations," IEEE Transactions on Wireless Communications, pp. 1-15, 2017. 